\title{
DUŠEVNO ZDRAVJE IN MIGRACIJE: UPORABNOST PROGRAMA PRVA POMOČ NA PODROČJU DUŠEVNEGA ZDRAVJA
}

\author{
Duška KNEŽEVIĆ HOČEVAR', Sanja CUKUT KRILIĆ"
}

COBISS 1.02

\section{IZVLEČEK}

\section{Duševno zdravje in migracije: Uporabnost programa Prva pomoč na področju duševnega zdravja}

Članek presoja uveljavljanje programa opismenjevanja o duševnem zdravju - Prva pomoč na področju duševnega zdravja - in njegove vpeljave med etnične manjšine in migrante. Osredotoča se na preoblikovanje programa v smeri kulturno občutljivih vsebin in metod izvajanja. Na podlagi evalvacije njihovih uporabnikov povzema predloge za nadaljnje izboljšave in prilagajanje njihovim »kulturnim potrebam«. Glede na rezultate omenjenih evalvacij članek opozarja na nujnost premika od upoštevanja "zgolj« kulturnih razsežnosti duševnega zdravja k obravnavi strukturnih ranljivosti, ki vplivajo na živete izkušnje migrantov, kar vključuje tudi kritično presojo samega koncepta opismenjevanja.

KLJUČNE BESEDE: migracije, duševno zdravje, opismenjevanje o duševnem zdravju, program Prva pomoč na področju duševnega zdravja, kulturna razsežnost

\section{ABSTRACT}

\section{Mental Health and Migration: The Applicability of the Mental Health}

\section{First Aid Program}

This article reviews the establishment of a mental health literacy program - Mental Health First Aid - and its introduction among ethnic minorities and migrants. The text focuses on the program adaptations toward culturally more sensitive content and approaches. Based on the evaluation of the program by its users, the article summarizes their suggestions for further adaptations to their "cultural needs." In line with the evaluations, the article discusses the shift from considering "only" the cultural dimensions of mental health toward reflecting structural vulnerabilities that affect lived experiences of migrants, including the contestable use of the literacy concept itself.

KEYWORDS: migration, mental health, mental health literacy, Mental Health First Aid, cultural dimension

Dr. zgodovinske antropologije; višja znanstvena sodelavka, Družbenomedicinski inštitut ZRC SAZU, Novi trg 2, SI-1000 Ljubljana; duska@zrc-sazu.si, https://orcid.org/0000-0003-3472-6005.

॥ Dr. socioloških znanosti; znanstvena sodelavka, Družbenomedicinski inštitut ZRC SAZU, Novi trg 2, SI-1000 Ljubljana; sanja.cukut@zrc-sazu.si, https://orcid.org/0000-0002-4498-3809. 


\section{UVOD}

V letih 2015 in 2016 sva avtorici članka sodelovali pri projektu Prepoznava in obravnava žrtev nasilja v družini v okviru zdravstvene dejavnosti. Med najinimi nalogami je bila priprava delavnice, $v$ kateri bi se presojale raznolike okoliščine, ki povzročajo, da osebe z izkušnjo nasilja $v$ družini, zlasti iz t. i. ranljivih skupin (med njimi tudi migrantke in migranti), ne poiščejo pomoči. Med delavnico se je izkazalo, da bi bilo namesto o ranljivih skupinah primerneje razpravljati o prepletu različnih oblik ranljivosti oseb z izkušnjo nasilja, in to z intersekcijskim pristopom (Lipovec Čebron 2019). $\checkmark$ esencialistične opise migrantk kot nosilk domnevnega seznama kulturnih značilnosti migrantske skupine ljudi ni zdrsnila le razprava o vinjeti, ki je opisovala izkušnjo nasilja $v$ družini migrantke. Udeleženke in udeleženci delavnic so kot pomembne okoliščine poudarili tudi družbenoekonomsko ozadje, dostopnost do zdravstvenih storitev ter prepričanja in domneve o družbeni nesprejemljivosti nasilja $v$ družinah migrantk kot okoliščin, ki bistveno vplivajo na to, da osebe z izkušnjo nasilja v družinah ne poiščejo pomoči.

Na podoben izziv obravnave »kulturne razsežnosti«, tokrat oseb z izkušnjo težav v duševnem zdravju, sva avtorici prispevka naleteli v psihoedukacijskem programu $Z$ večjo pismenostjo o duševnem zdravju do obvladovanja motenj razpoloženja (OMRA). ${ }^{1}$ Kljub izhodiščem programa, ki se opirajo na uveljavljeni koncept opismenjevanja o duševnem zdravju $v$ skladu $z$ diagnostičnimi merili mainstreamovske zahodne psihiatrije, ${ }^{2}$ avtorici članka ob sprotnih kvalitativnih evalvacijah uporabnosti programa obenem analizirava mednarodno znanstveno literaturo, ki kritično presoja uporabnost programov Prve pomoči na področju duševnega zdravja. Tega ne počneva le $z$ namenom bolj obveščenega in kritičnega presojanja uporabnosti samega programa, ki je okrnjena slovenska različica programa Prve pomoči na področju duševnega zdravja. To počneva, ker večdisciplinarna ekipa programa ${ }^{3}$ kljub konceptualnim razhajanjem o obravnavi duševnega zdravja oz. izkušenj duševnih motenj (prim. Lipovec Čebron 2019) namerava vsebino programa razširiti na potrebe »opismenjevanja« o duševnem zdravju ljudi iz različnih ranljivih skupin, tudi migrantk in migrantov. Poseben izziv bo prav oblikovanje kulturno občutljivega programa, ki ne podlega statični in esencialistični predstavi o kulturi njenih udeleženk in udeležencev.

Glede na vedno večjo družbeno relevantnost in naraščajočo raznolikost migracij tako na nacionalni kot na globalni ravni ne preseneča, da tudi med strokovnjaki in

1 Program krepitve duševnega zdravja OMRA je med letoma 2017 in 2019 sofinanciralo Ministrstvo za zdravje RS. Isto ministrstvo sofinancira tudi njegovo nadaljevanje, tokrat z naslovom Opismenjevanje o motnjah razpoloženja in osebnostnih motnjah (2020-2022).

2 V Sloveniji se za kodiranje duševnih motenj trenutno uporablja posodobljena avstralska modifikacija desete revizije Mednarodne klasifikacije bolezni in sorodnih zdravstvenih problemov za statistične namene, MKB-10-AM, verzija 6.

3 V ekipi OMRA sodelujemo raziskovalke in raziskovalci iz psihiatrije, psihologije, socialnega dela, sociologije, politologije, filozofije in antropologije. 
strokovnjakinjami, ki se ukvarjajo z migracijami in duševnim zdravjem, naraščajo prizadevanja za oblikovanje omenjenim skupinam prilagojenih oblik pomoči in obravnave (Cukut Krilić 2019; WHO 2017). Zlasti v bolj družboslovno in humanistično usmerjenih raziskavah dejavniki tveganja za težave $v$ duševnem zdravju niso le individualni (osebnostni), temveč izhajajo tudi iz t. i. skupne kulture oz. kulturnega ozadja; zaradi njih naj bi migranti in migrantke duševne stiske doživljali na podoben način. Tako $v$ sodobnih družbah izseljevanja kot priseljevanja so vedno bolj $\checkmark$ ospredju družbenopolitične in ekonomske razmere. Pomembno jih oblikujejo neenakosti v družbeni moči posameznih skupin prebivalstva, kar uokvirja njihovo doživljanje in spoprijemanje s težavami v duševnem zdravju (Arsenijević idr. 2018). Raziskovalci in raziskovalke poudarjajo, da migranti in migrantke zaradi diskriminacije $v$ družbah preselitve, ki se na primer kaže v neenaki obravnavi v zdravstvu, lahko tudi značilno manj pogosto uporabljajo storitve na področju duševnega zdravja kot pa »lokalno prebivalstvo« (Lindert idr. 2008). V nedavnem pregledu raziskav, ki so $v$ »splošni populaciji« analizirale ovire za neiskanje pomoči ob težavah $v$ duševnem zdravju, so raziskovalci in raziskovalke kot ključna dejavnika poudarili prav pomanjkanje znanja o težavah v duševnem zdravju in stigmo kot spremljajočo okoliščino (Gulliver idr. 2010).

Zaradi raznolikih dejavnikov ranljivosti, ki vključujejo obdobje pred, med in po migraciji, so migranti in migrantke gotovo skupina, katere znanje o duševnem zdravju in iskanje pomoči zahtevata posebno pozornost. Zastavlja se vprašanje, čigavo znanje o duševnem zdravju, ki naj bi omogočilo pravočasno iskanje strokovne pomoči migrantk in migrantov $s$ težavami $v$ duševnem zdravju, je $v$ ospredju prizadevanj za njegovo izboljšanje.

S tega stališča prvi del besedila povzema kratek oris okoliščin uveljavljanja programa Prve pomoči na področju duševnega zdravja $v$ Avstraliji. $V$ nadaljevanju se osredotoča na njegovo vpeljavo $v$ skupnostih, ki jih oblikovalci in oblikovalke politik in raziskovalci in raziskovalke označujejo za »kulturno drugačne« od večinskega prebivalstva posameznih nacionalnih držav; npr. staroselsko in priseljensko prebivalstvo. Besedilo se opira na evalvacijske raziskave kulturno občutljivih programov Prve pomoči na področju duševnega zdravja, ki so med drugim opozorile na nujnost nadaljnjega prilagajanja izobraževalnih vsebin in metod t. i. kulturnim razsežnostim razumevanja duševnega zdravja omenjenih skupin prebivalstva. Tovrstna prizadevanja so prikazana tako s primeri prilagojenih programov Prve pomoči na področju duševnega zdravja za etnične manjšine oz. t. i. staroselsko prebivalstvo kot njihovega prilagajanja za migrante in migrantke $v$ različnih državah. Skladno z evalvacijskimi raziskavami besedilo ne presoja le vprašanja vpeljave kulturne razsežnosti duševnega zdravja v tovrstne programe, temveč tudi obravnave zgodovinskih in sodobnih strukturnih ranljivosti, ki pomembno sooblikujejo živete izkušnje ljudi s težavami v duševnem zdravju. 


\section{OPISMENJEVANJE O DUŠEVNEM ZDRAVJU}

Programi »opismenjevanja« o duševnem zdravju izvorno izhajajo iz Avstralije. Svetovno najbolj prepoznan in razširjen program, ki se izvaja na ravni skupnosti, je Prva pomoč na področju duševnega zdravja (angl. Mental Health First Aid - MHFA). Utemeljen je v konceptu opismenjevanja po zgledu 'zdravstvenega opismenjevanja' (angl. health literacy), ki je že vsaj pol stoletja uveljavljen koncept $v$ medicinskem akademskem diskurzu (Nutbeam 2000).

Na prehodu v novo tisočletje je Anthony F. Jorm s soavtorji koncept opismenjevanja na področju duševnega zdravja opredelil kot tista "[...] znanja in prepričanja o duševnih motnjah, ki prispevajo k njihovemu prepoznavanju, obvladovanju ali preprečevanju [...]« (Jorm idr. 1997: 182).

Opismenjevanje oz. izobraževanje o duševnem zdravju se opira na predstave in kategorije težav $v$ duševnem zdravju t. i. zahodnega medicinskega modela. Njegov cilj je izboljšati tako sposobnost ljudi za prepoznavanje posamičnih težav $v$ duševnem zdravju kot njihovo znanje o vzrokih in dejavnikih tveganja za tovrstne težave in razpoložljivi pomoči. Izvajalke in izvajalci opismenjevanja o duševnih motnjah v skladu s klasifikacijo oz. z diagnostičnimi merili Ameriškega psihiatričnega društva APA kot orodje uporabljajo vinjete za opis osebe z določeno motnjo razpoloženja (npr. depresijo ali anksiozno motnjo). Merila so zabeležena v Diagnostičnem in statističnem priročniku duševnih motenj DSM-IV ${ }^{4}$ oz. mednarodni klasifikaciji bolezni in sorodnih zdravstvenih problemov za statistične namene, avstralski modifikaciji (ICD-10-AM) (Lam idr. 2010). Vse našteto naj bi zmanjšalo tudi družbeno razdaljo do ljudi s težavami v duševnem zdravju oz. znižalo njihovo stigmatizacijo. Obenem se zagovorniki te oblike psihoedukacijskega programa sklicujejo na odmevne ugotovitve raziskav, ki potrjujejo, da je v družbah z višjo ravnjo pismenosti o duševnem zdravju opaziti boljše duševno zdravje ljudi, ki pogosteje pravočasno poiščejo strokovno pomoč in se v večjem obsegu lotevajo preventivnih strategij (Hadlaczky idr. 2014; Jorm 2012).

Leta 2001 sta v Avstraliji prav Jorm in Betty Kitchener oblikovala prvo izobraževanje MHFA. Betty Kitchener, takrat prostovoljka z živeto izkušnjo težav $v$ duševnem zdravju, je postala izvajalka tovrstnih izobraževanj oz. strokovnjakinja po izkušnji. Podoben medicinski model prve pomoči za poškodbe in urgentne situacije sta prilagodila problematiki duševnega zdravja s ciljem, da se človeku, ki oboleva ali je v duševni stiski, pomoč zagotovi še preden poišče primerno strokovno pomoč ali razreši svojo krizo. To izobraževanje ljudi v določeni skupnosti uči, kako prepoznati skupino simptomov t. i. splošnih duševnih motenj (npr. depresije in anksioznosti) in kriznih situacij (npr. samomorilnega razmišljanja in vedenja, akutnih stresnih odzivov, napadov panike in akutnih psihotičnih vedenj), kako zagotoviti začetno pomoč in človeka usmeriti v primerno obravnavo in druge oblike razpoložljive pomoči (Kitchener, Jorm 2002).

Najnovejša različica DSM-V je v uporabi od leta 2013. 
Program MHFA se je iz Avstralije zelo hitro razširil po svetu; po zadnjih podatkih ga je vsebinsko prilagodilo še 24 držav, od tega 11 evropskih (MHFA international). ${ }^{5}$ Poleg standardnega izobraževanja, namenjenega odraslim $s$ težavami $v$ duševnem zdravju, so ga tako v Avstraliji kot po svetu prilagodili različnim starostnim in poklicnim družbenim skupinam - med drugim tudi pripadnicam in pripadnikom različnih etničnih skupnosti. Pokazalo se je, da splošni pristop, ki ga ponazarja metafora »ena velikost ustreza vsem«, ni primeren in da je treba upoštevati tako kulturno raznolikost prebivalcev Avstralije kot tudi njenih etničnih skupin.

\section{KULTURNO OBČUTLJIVI MHFA ZA ETNIČNE MANJŠINE V AVSTRALIJI}

Avtorji MHFA so najprej preuredili program za avstralske Aborigine in prebivalce otokov Torres Strait, ki predstavljajo 2,4 odstotka nacionalnega prebivalstva oz. okoli pol milijona ljudi. Nacionalne zdravstvene evidence so namreč sporočale, da imajo v primerjavi z večinskim prebivalstvom prav te skupine visoke stopnje telesnih obolenj, nižjo pričakovano življenjsko dobo in visoke stopnje težav v duševnem zdravju. Številni med njimi živijo v neugodnih življenjskih okoljih in nastanitvah ter razpolagajo z nizkimi prihodki. Avtorje MHFA je k preoblikovanju standardnega MHFA programa za splošno odraslo prebivalstvo spodbudil zlasti podatek, da večina staroselskih skupnosti ni bila deležna nikakršnega izobraževanja o obvladovanju težav v duševnem zdravju ali kriznih situacij (Kanowski idr. 2009).

Med letoma 2004 in 2006 je posvetovanje s skupinami avstralskih Aboriginov in prebivalcev otokov Torres Strait o standardnem MHFA pokazalo, da je treba določene vsebine in metode preoblikovati glede na njihove »kulturne potrebe«. Leta 2007 so pred izvedbo prvega izobraževanja med drugim prilagodili gradivo in vanj vključili vsebine, ki so potrdile njihovo psihološko odpornost na več stoletij izvajanja rasizma, razlastitev in nasilja ter na doživljanje travm in izgub, ki so jih utrpeli od prihoda kolonizatorjev $v$ 17. stoletju (npr. nasilno preselitev njihovih skupnosti $v$ misijone in rezervate, sistemsko zanikanje njihovih jezikov in kultur, zatiranje političnih in drugih človekovih pravic, izgubo otrok zaradi prisilnega odvzema itd.). $\checkmark$ vsa izobraževalna gradiva in priročnike so vključili svoje umetniške stvaritve in z njimi ilustrirali pomembna sporočila o lastnih konceptih duševnega zdravja in dobrega počutja. Tako Aborigini kot prebivalci otokov Torres Strait so se v primerjavi z

5 Prilagojene MHFA s svojim nacionalnim zdravstvenim sistemom izvajajo v Avstraliji, Angliji, Bangladešu, na Bermudskem otočju, Danskem, Finskem, v Hongkongu, Indiji, na Japonskem, v Kambodži, Kanadi, na Malti, Nizozemskem, Novi Zelandiji, v Pakistanu, Republiki Irski, na Severnem Irskem, v Savdski Arabiji, Singapurju, na Škotskem, Švedskem, v Švici, Združenih arabskih emiratih, ZDA in Wellsu. Jorm idr. (2019) ocenjujejo celo, da se je do srede leta 2018 programa MHFA udeležilo več kot 700.000 prebivalcev Avstralije in 2,7 milijona ljudi po svetu; osveženi spletni podatki (januar 2021) sporočajo, da se je izobraževanj udeležilo preko štiri milijone ljudi po svetu (MHFA international). 
"zahodnimi« pojmovanji in kategorizacijami duševnega zdravja s tovrstnimi sporočili laže identificirali in se bolj udeleževali tovrstnih izobraževanj (Kanowski idr. 2009).

Leta 2007 je evalvacija prvega izobraževanja kulturno občutljivega MHFA za predavatelje, ki so bili večinoma iz skupnosti Aboriginov in prebivalci otokov Torres Strait, pokazala, da so nujne še dodatne izboljšave. Poleg praktičnih popravkov npr. več odmorov med izobraževanji zaradi velike količine posredovanih informacij, ki jih udeleženke in udeleženci niso utegnili sproti predelati - so izvajalke in izvajalci izobraževanj predlagali več prilagoditev za manj izobražene udeleženke in udeležence, ki se bolje učijo z izvajanjem vaj kot branjem. Obenem so opozorili na heterogenost Aboriginov in prebivalcev otokov Torres Strait in se zavzeli za stalno prilagajanje kulturno občutljivega programa MHFA kulturnim posebnostim tako določenih skupin kot tudi lokalnim skupnostim, v katerih se program izvaja (Kanowski idr. 2009).

Domnevno nizka pismenost o duševnem zdravju in kulturno neobčutljive prakse izvajalk in izvajalcev splošnih nacionalnih zdravstvenih storitev naj bi bile razlog, da etnične manjšine $v$ Avstraliji niso iskale strokovne pomoči. Zato so se oblikovalci in oblikovalke kulturno občutljivih MHFA zavzeli za uresničevanje standardov t. i. kulturne kompetence tako v izobraževanju kot socialnozdravstvenih storitvah. Kulturi prilagojena zdravstveno varstvo oz. kulturno kompetentna skrb sta s perspektive kulturnih kompetenc med najpomembnejšimi dejavniki zmanjševanja neenakosti v zdravju in pri doseganju ugodnejših izidov zdravljenja (Fortier, Bishop v Shaw idr. 2008). Izboljševanje kulturnih kompetenc $v$ zdravstvu bi npr. pomenilo, da so storitve zdravstvenega varstva dostopnejše, primernejše in učinkovitejše tudi za osebe iz različnih kulturnih in etničnih skupin in da so zdravstveni delavci vedno bolj usposobljeni za njihovo obravnavo (Kirmayer 2012; Lipovec Čebron, Huber 2020). Toda kulturna občutljivost je $v$ tem primeru razumljena kot prilagoditev zagotavljanja storitev in skrbi domnevnim »kulturnim posebnostim « določenih etničnih skupin, a se pri tem spregleda vprašanje, ali so tovrstne skupine dejansko "kulturno homogene« (Ingleby 2005; Kirmayer 2012). Oblikovalci in oblikovalke različnih programov usposabljanj, ki upoštevajo kulturne razlike, namreč pogosto ne prevprašajo teoretskih predpostavk koncepta kulture. To pomeni, da določeno kulturo obravnavajo kot homogeno in skoraj nespremenljivo entiteto, ljudi pa kot njene pasivne nosilce. Nadalje kulturo pogosto enačijo s konceptoma etničnosti in rase, pri čemer spregledajo raznovrstne socioekonomske neenakosti, ki jih izkušajo domnevno »kulturno različne« skupine prebivalstva (Lipovec Čebron, Huber 2020).

Oblikovalci in oblikovalke kulturno občutljivih MHFA programov so obenem potrdili, da kulturno občutljiva razlaga duševnega zdravja ni nujno komplementarna z bio-psiho-socialnim modelom zahodne medicine, uporabljenim $v$ standardnih MHFA. To jih je spodbudilo, da so s strokovnjaki in strokovnjakinjami na področju duševnega zdravja iz skupnosti Aboriginov in prebivalcev otokov Torres Strait s pomočjo Delfi metode oblikovali konsenz za kulturno občutljiva navodila za izobraževanja MHFA; ta naj bi se v obeh skupnostih izvajala po celotni državi. Navodila poudarjajo zlasti pomen razumevanja simptomov v lokalnem kulturnem kontekstu, pri čemer 
je treba upoštevati pestrost potreb posameznikov in posameznic, in to ne glede na njihovo kulturno identiteto in pomembno vlogo družine in skupnosti pri krepitvi pozitivnih odnosov med člani in članicami kot varovalnih dejavnikov ljudi s težavami v duševnem zdravju (Hart idr. 2009; 2010).

\section{EVALVACIJA KULTURNO OBČUTLJIVIH MHFA PO SVETU}

Evalvacije programov MHFA, ki so jih po svetu izvajali za t. i. staroselsko prebivalstvo ter migrantke in migrante, so prav tako potrdile nujnost upoštevanja kulturne razsežnosti duševnega zdravja. V Kanadi so Monique Auger idr. (2019) evalvirali že od leta 2012 kulturno prilagojena MHFA izobraževanja, ki so jih izpeljali v šestih skupnostih s prebivalstvom t. i. prvotnih ljudstev, ${ }^{6}$ da bi na njeni podlagi zanje dorekli oz. izboljšali kulturno občutljivo različico MHFA.

$\checkmark$ primerjavi z avstralsko si je kanadska inačica prizadevala uveljaviti koncept 'kulturne varnosti' (angl. cultural safety), ${ }^{7} v$ katerem so upoštevali posledice zgodovinske medgeneracijske travme staroselskega prebivalstva. Te se med drugim izražajo tudi $v$ njihovem doživljanju nesorazmerno več težav $v$ primerjavi z večinskim prebivalstvom, in to tako $v$ družbenem življenju kot duševnem zdravju. Koncept kulturne varnosti, ki naj bi dopolnjeval koncept kulturne kompetence, še bolj poudarja kritični premislek o moči in privilegijih kulture samih izvajalk in izvajalcev socialnozdravstvenih praks prevladujočega zahodnega medicinskega modela oz. dinamiko moči med uporabnicami in uporabniki zdravstvenih storitev in njihovimi izvajalkami in izvajalci (Isaacson v Auger idr. 2019).

Evalvacija uresničevanja kulturne varnosti v že kulturno prilagojenem MHFA za kanadsko staroselsko prebivalstvo je pokazala na nujnost izboljšav. Čeprav so kot dobrodošle in uporabne omenjali izobraževalne vsebine, ki vključujejo kontekstualizacijo travme v obdobju kolonizacije staroselskega prebivalstva, so poudarili, da je poleg zgodovinskih treba upoštevati tudi tiste sedanje okoliščine njihovih življenj, ki jih doživljajo kot travmatične. Nekateri so za uresničevanje koncepta kulturne varnosti predlagali dodatno prilagoditev izobraževalnih vsebin posebnostim lastne lokalne skupnosti, sklicujoč se tako na heterogenost staroselske zgodovine kot na sedanje vzroke strukturne ranljivosti. Poudarili so tudi, da je t. i. dvoočesni pristop,

$6 \quad$ V Kanadi je prebivalstvo t. i. 'prvotnih ljudstev' (angl. first nations) uradni izraz za skupino ljudi, ki jih poleg Inuitov in Métisev (potomcev Evropejcev in staroselcev) uvrščajo med 'staroselsko prebivalstvo' (angl. Indigenous Peoples). Inuiti živijo pretežno na severnih, arktičnih območjih Kanade, Métise na ruralnem območju nižinskih step Ontaria, prvotna ljudstva pa naseljujejo celotno območje Kanade južno od arktičnega roba in živijo pretežno v rezervatih (First Nations Studies Program).

7 Koncept kulturne varnosti je oblikovala maorska medicinska sestra Irihapeti Ramsden z Nove Zelandije, s ciljem, da bi si izvajalke in izvajalci zdravstvenih storitev prizadevali prepoznati, spoštovati in vzdrževati enkratne kulturne identitete maorskega prebivalstva in varno uresničevati njihove potrebe, pričakovanja in pravice (Ramsden 1993; Browne idr. 2005). 
ki naj bi zagotavljal tako staroselske kot uradne, $\mathrm{tj}$. zahodne zdravstvene razlage duševnega zdravja, v MHFA še vedno $v$ korist slednjih. Kot stigmatizirajoče so omenili tudi navedbe facilitatorjev o nizki ravni znanja staroselskega prebivalstva o duševnem zdravju. Taki poudarki naj bi nevtralizirali koncepta celovitosti in ravnovesja med obema stališčema oz. ohranjali hierarhijo med njima v korist zahodnega bio-medicinskega znanja. Med nujnimi izboljšavami so predlagali še močnejše sodelovanje s svojimi lokalnimi skupnostmi, natančnejšo opredelitev, kaj duševno zdravje in dobro počutje pomenita njim, in boljšo razlago, kako lahko tako tradicionalni kot zahodni viri podpore prispevajo k celovitemu zdravju in dobremu počutju t. i. staroselskega prebivalstva (Auger idr. 2019).

\section{MHFA ZA MIGRANTKE IN MIGRANTE}

Podobne dileme »opismenjevanja« o duševnem zdravju so se pokazale tudi v različicah MHFA za migrantke in migrante. Tudi ta družbena skupina je bila na podlagi zdravstvene evidence o nizki stopnji uporabe storitev na področju duševnega zdravja in nizki stopnji »pismenosti« prepoznana kot skupina, ki potrebuje izobraževanje. Kljub temu so evalvacije kulturno prilagojenih MHFA programov za migrantke in migrante načele vprašanje enotnosti t. i. »kulturnih prepričanj«. Povedni primer so raziskave o pismenosti o duševnem zdravju med kitajsko skupnostjo v različnih priseljenskih državah po svetu. Raziskava Daniela Wonga idr. (2012) med skupnostjo Kitajcev v Avstraliji in v Hong Kongu je pokazala njihovo nizko raven pismenosti v primerjavi z »večinskim prebivalstvom «. To so avtorji študije prepoznali npr. v njihovem slabšem prepoznavanju depresije in shizofrenije ter v slabšem znanju o medicinskih oblikah zdravljenja duševnih motenj (na primer o zdravilih in hospitalizacijah) (Wong idr. 2012).

Evalvacija uporabnosti MHFA za avstralsko, tako kantonsko kot mandarinsko govorečo kitajsko skupnost v Melbournu, je pokazala tudi nizko stopnjo sprejemanja iskanja strokovne pomoči oz. strokovne obravnave v primeru shizofrenije (Lam idr. 2010). Na eni strani naj bi še vedno šlo za močno izraženo stigmo, ki jo ima shizofrenija v kitajski skupnosti. ${ }^{8} \mathrm{Ne}$ le, da izraz razumejo skrajno negativno in da psihotičnim stanjem shizofrenije pogosto pripisujejo znake norosti; domnevno naj bi shizofrenijo kot izkušnjo psihotičnega obolenja pogosto zanikali oz. naj bi zanjo, skladno z njihovo družbeno resničnostjo in moralnimi svetovi, uporabljali sprejemljivejše oznake. ${ }^{9}$ Na drugi strani je evalvacija pokazala, da na njene izide lahko vplivajo same izobraževalne metode. Večji del izobraževanja, ki je potekalo v kantonščini, je bil simultano

8 Neenakosti in izključevanj migrantov in migrantk ne zaznavamo le $v$ njihovih izvornih državah in državah preselitve, temveč so vir tovrstnih izključevanj lahko tudi same transnacionalne skupnosti (Bofulin 2020).

9 Več o antropoloških razlagah stigme v duševnem zdravju med kitajsko govorečimi priseljenkami in priseljenci v ZDA glej Knežević Hočevar 2020. 
prevajan $v$ mandarinščino. Čeprav naj bi udeleženke in udeleženci MHFA razumeli obe pisni različici jezikov, se njuna izgovarjava precej razlikuje, kar naj bi domnevno vplivalo tudi na razumevanje posredovanih vsebin mandarinsko govorečih udeleženk in udeležencev izobraževanj (Lam idr. 2010).

Nehomogenost »kitajske kulture« je potrdila tudi raziskava Cha-Hsuan Liuja idr. (2015), ki je presojala podpovprečno uporabo storitev na področju duševnega zdravja med etničnimi Kitajci na Nizozemskem. Avtorji raziskave ugotavljajo, da so na Nizozemskem v ozadju te neuporabe $v$ manjši meri ovire, ki jih raziskave $v$ številnih zahodnih državah pripisujejo kulturnim prepričanjem te skupnosti (npr. dvomu $v$ zahodne metode medicinske obravnave, prednostno iskanje pomoči pri kitajskih tradicionalnih zdravilcih, enačenje izkušnje duševnega obolenja z norostjo, sramoti duševnega obolenja za družino itd.). Liu idr. (2015) so v kvalitativni raziskavi, v kateri je sodelovalo 25 udeleženk in udeležencev kitajske etnične skupnosti, ${ }^{10}$ potrdili, da je neuspešno zagotavljanje primernih zdravstvenih storitev za to skupino prebivalstva lahko večji vzrok neiskanja pomoči kot pa zgolj sklicevanje na njihova domnevno enotna kulturna prepričanja. Med razlogi za neiskanje strokovne pomoči poudarjajo praktične ovire, kot je dostop do zdravstvenega sistema na Nizozemskem, npr. nezadostno znanje nizozemskega jezika za opis težav v duševnem zdravju, pomanjkljivo znanje o delovanju zdravstvenega sistema, nezavedanje o potrebi po strokovni pomoči, strah pred diagnostiko, ki bi jih zaznamovala kot duševno bolne, negativna stališča do zdravstvene obravnave, tj. doživljanje diskriminacije in stigmatizacije kulturno neusposobljenega zdravstvenega osebja itd. Obenem pa med ovire spada tudi izkušnja obravnave, tj. dvom $v$ pravilnost zahodne diagnostike in obravnave, strah pred stranskimi učinki zdravil, nevztrajanje $v$ obravnavi zaradi lastnih dolgih delovnih urnikov itd. (Liu idr. 2015).

Kulturne okoliščine, ki pomembno določajo pismenost o duševnem zdravju, so na primeru skupnosti migrantk in migrantov iz držav Vzhodne Azije (Kitajske, Hong Konga, Japonske, Koreje in Tajvana) v različnih zahodnih državah proučevali tudi Sumin Na idr. (2016); pregledali so že opravljene študije. Tudi omenjene skupine migrantov in migrantk praviloma v manjši meri kot »večinsko « prebivalstvo uporabljajo storitve služb na področju duševnega zdravja, pomoč tovrstnih služb poiščejo prepozno in zgolj v primeru hujših težav, čeprav naj bi imeli podobne prevalence težav v duševnem zdravju kot domače prebivalstvo. $V$ raziskavi so se osredotočili na naslednje elemente koncepta pismenosti o duševnem zdravju: prepoznava simptomov duševnih motenj, prepričanja o vzrokih in dejavnikih tveganja zanje, poznavanje oblik pomoči in samopomoči v primeru blažjih težav.

Pregled je pokazal, da je ta skupina migrantov in migrantk težave $v$ duševnem zdravju praviloma manj pogosto opisovala z uveljavljenimi psihiatričnimi diagnozami in s terminologijo medicinske stroke države njihove priselitve, da je njihovo

10 Sicer številčno majhen vzorec je vključeval skupine, heterogene po starosti, spolu, izobrazbi in poklicu - tj. prvo in drugo generacijo migrantk in migrantov, ki so na Nizozemsko prišli bodisi iz različnih regij Kitajske bodisi iz nekdanjih nizozemskih kolonij. 
znanje o vzrokih težav $v$ duševnem zdravju različno, da bolj negativno sprejemajo službe, ki se ukvarjajo z duševnim zdravjem, in da se v večji meri kot »večinsko« prebivalstvo zanaša na različne oblike samopomoči. Hkrati so opozorili, da znanje o težavah v duševnem zdravju ni nujno neposredno povezano $z$ dejanskimi načini iskanja pomoči. Ker se izrazi stisk in trpljenja vedno oblikujejo v kulturnem kontekstu, zgolj podajanje »pravilne« psihiatrične diagnoze za nekatere skupine migrantov in migrantk nima posebnega smisla, svoje težave razumejo na drugačen način in se raje odločajo za alternativne načine zdravljenja in/ali zdravilstva. Vključevanje tovrstnih razumevanj duševnega zdravja v modele oblikovanja skrbi je bil za avtorje ključni element spodbujanja iskanja pomoči tudi med to skupino prebivalstva. Tako kot že prejšnje študije pa so poudarili tudi strukturne okoliščine, ki včasih odločilno vplivajo, da ljudje pomoči ne poiščejo: nepridobljeni pravni status, slabo znanje jezika »večinskega prebivalstva«, različne oblike diskriminacije in omejen dostop do kulturno primernih oblik pomoči.

Podobno kot v primeru prilagajanja MHFA staroselskim skupnostim so evalvacije kulturno prilagojenih MHFA za migrantske skupnosti potrdile potrebo po bolj dostopnih in zanesljivih informacijah o delovanju strokovnih sistemov pomoči, večji vključitvi njihovega osebja v zdravstveni sistem kot tudi po izboljšanju prevajalskih storitev oz. uvedbe instituta interpreta. Ta bi tam, kjer ga še ni, izboljšal komunikacijo med izvajalci in izvajalkami ter uporabnicami in uporabniki storitev. Skupno vsem omenjenim evalvacijam je, da je prav zaradi uporabljene zahodne psihiatrične terminologije, ki se opira na tehniko vinjet za prepoznavo prototipskih bolnikov, ali pa izjav o stališčih za identifikacijo prepričanj (Furnham, Hamid 2014) nujen bolj kulturno specifičen pristop MHFA. Pokazala se ni le potreba po vključitvi »imigrantskih vsebin « v izobraževalni program (kot npr. vključevanje njihovih zgodb in izkušenj tako pred emigracijo, med njo in po njej, razprav o kulturno kompetentnem strokovnem osebju, več nasvetov glede obvladovanja kriznih situacij itd.), ampak tudi potreba po sodelovanju in vključevanju zaposlenih v zdravstvenih organizacijah in številnih drugih organizacijah socialnih storitev $v$ skupnem prizadevanju za zagotavljanje pomoči migrantkam in migrantom na vseh ravneh socialnozdravstvene oskrbe (Lee, Tokmic 2019).

\section{ZAKLJUČEK}

Čeprav so evalvacije programov Prve pomoči na področju duševnega zdravja potrdile, da tovrstno izobraževanje izboljša znanje njegovih uporabnic in uporabnikov o opredeljevanju težav $v$ duševnem zdravju, jih motivira za iskanje razpoložljivih oblik strokovne pomoči in znižuje družbeno razdaljo do ljudi s težavami v duševnem zdravju, so obenem odprle številna vprašanja in pasti glede razumevanja kulture tako uporabnic in uporabnikov kot tudi izvajalk in izvajalcev izobraževanj. 
Že kmalu po njihovi vpeljavi se je pokazalo, da ni mogoče oblikovati univerzalnih izobraževalnih vsebin o duševnem zdravju, ki bi jih lahko neproblematično uporabljali za različne »kulturne skupine« prebivalstva. Iz tega razloga so se strokovnjaki in strokovnjakinje lotili preoblikovanja programov Prve pomoči na področju duševnega zdravja za različne poklicne in starostne skupine ljudi, med drugim tudi za staroselske in priseljenske skupnosti. Pri njih so izobraževalne vsebine in metode skušali prilagoditi njihovemu razumevanju duševnega zdravja in dobrega počutja. Ti niso bili nujno usklajeni s prevladujočim "zahodnim medicinskim modelom obravnave duševnih obolenj. Prav ta ugotovitev je potrdila, da pri tovrstnih izobraževanjih ni treba upoštevati le kulture uporabnic in uporabnikov, temveč tudi njihovih izvajalk in izvajalcev oz. same biomedicinske obravnave duševnega zdravja, ki se ni osvobodila določene kulture (angl. culture-free).

Evalvacije raziskav že izpeljanih t. i. kulturno občutljivih programov Prve pomoči na področju duševnega zdravja so potrdile, da se tudi kultura $v$ tako preoblikovanih programih pogosto neproblematično enači s t. i. kulturnimi prepričanji (npr. kitajska prepričanja) sicer družbeno heterogenih skupin udeležencev in udeleženk, še zlasti, ko se jo razume kot sinonim etničnosti ali govorjenega jezika. Evalvacije uporabnic in uporabnikov izobraževanj so sporočale potrebo po nadaljnjem prilagajanju programov posebnim lokalnim skupnostim in heterogenim skupinam staroselskega ali priseljenskega prebivalstva.

Da kultura ni vselej odločilna, da posamezniki in posameznice ne poiščejo strokovne pomoči, so potrdile raziskave, ki so opozorile na njihove strukturne ranljivosti oz. pomanjkljivosti obstoječih socialnozdravstvenih sistemov priseljenskih držav glede zagotavljanja dostopnosti svojih storitev za omenjene skupine ljudi. Nekateri raziskovalci in raziskovalke se zato zavzemajo za vpeljavo koncepta strukturnih (in ne zgolj kulturnih) kompetenc, kjer je v ospredju vprašanje, kako »kultura« in »struktura« sooblikujeta izkušnje številnih oblik stigmatizacij in neenakosti. Vsaka interakcija strokovnjakov in strokovnjakinj na področju (duševnega) zdravja je bolj kot odraz domnevnih »kulturnih posebnosti uporabnikov in uporabnic« izraz njihovih strukturnih ranljivosti (Metzl, Hansen 2014).

Zagovorniki in zagovornice prizadevanj za kulturno preoblikovanje programov Prve pomoči na področju duševnega zdravja za staroselsko in priseljensko prebivalstvo se vedno bolj zavedajo, da kultura ni le okoliščina udeleženk in udeležencev programov, ampak tudi njenih oblikovalk in oblikovalcev ter izvajalk in izvajalcev. S tega stališča sta problematična sama izraza "pismenost« in »opismenjevanje«, ki implicirata in prednostno podpirata posebno vrsto znanja, ki se posreduje kot univerzalno znanje in v odnosu do katerega se ugotavlja tudi večjo oz. nižjo pismenost določenih skupin prebivalstva. Izraza tudi ne preverjata moči zagovornic in zagovornikov določene »kulture« znanja (npr. o duševnem zdravju), ki je v komunikaciji $z$ uporabnicami in uporabniki praviloma hierarhično posredovana. Še vedno ostaja aktualen poziv Arthurja Kleinmana in Petra Bensona, naj zdravstveno osebje $v$ enakovredni komunikaciji s pacienti uporabi »mini-etnografijo« (Kleinman, Benson 
2006: 1674), s katero svoje strokovno znanje postavi ob bok pacientu, ne pa višje od pacienta ali nad njegove razlage in mnenja.

\section{LITERATURA}

Arsenijević, Jovana, Burtscher, Doris idr. (2018). "I Feel Like I am Less than Other People": Health-related Vulnerabilities of Male Migrants Travelling Alone on their Journey to Europe. Social Science and Medicine 209, 86-94, http://10.1016/j. socscimed.2018.05.038 (19. 1. 2019).

Auger, Monique, Crooks, Claire V. idr. (2019). The Essential Role of Cultural Safety in Developing Culturally-relevant Prevention Programming in First Nations Communities: Lessons Learned from a National Evaluation of Mental Health First Aid First Nations. Evaluation and Program Planning 72, 188-196, https://doi. org/10.1016/j.evalprogplan.2018.10.016 (2. 2. 2020).

Bofulin, Martina (2020). Kitajski migranti in covid-19: Mobilnost in izključevanje med pandemijo. Dve Domovini / Two Homelands 52, 95-111, https://doi.org/10.3986/ dd.2020.2.0 6 (12. 3. 2021).

Browne, Annette J., Smye Victoria L., Varcoe, Colleen (2005). The Relevance of Postcolonial Theoretical Perspectives to Research in Aboriginal Health. Canadian Journal of Nursing Research 37/4, 16-37, https://cjnr.archive.mcgill.ca/article/ view/1969 (3. 12. 2020).

Cukut Krilić, Sanja (2019). Duševno zdravje v kontekstu sodobnih migracij. Z večznanjao motnjah razpoloženja do izhodov iz labirintov: Izkušnje in razmisleki (ur. Lilijana Šprah). Ljubljana:Založba ZRC, ZRC SAZU, 245-253, https://doi.org/10.3986/9789610502197 (3. 12. 2020).

First Nations Studies Program 2009, https://indigenousfoundations.arts.ubc.ca/terminology (5. 12. 2020).

Furnham, Adrian, Hamid, Aseel (2014). Mental Health Literacy in Non-western Countries: A Review of the Recent Literature. Mental Health Review Journal 19/2, 8498, https://doi.org/10.1108/MHRJ-01-2013-0004 (29. 11. 2020).

Gulliver, Amelia, Griffiths, Kathleen M., Christensen, Helen (2010). Perceived Barriers and Facilitators to Mental Health Help-seeking in Young People: A Systematic Review. BMC Psychiatry 10/113, 1-9, https://doi.org/10.1186/1471-244x-10-113 (7. 1. 2021).

Hadlaczky, Gergö, Hökby, Sebastian idr. (2014). Mental Health First Aid is an Effective Public Health Intervention for Improving Knowledge, Attitudes, and Behaviors: A Meta-Analysis. International Review of Psychiatry 26/4, 467-475, https://doi.org/ 10.3109/09540261.2014.924910 (2. 7. 2019).

Hart, Laura M. idr. (2009). Mental Health First Aid for Indigenous Australians: Using Delphi Consensus Studies to Develop Guidelines for Culturally Appropriate 
Responses to Mental Health Problems. BMC Psychiatry 9, 47, https://doi. org/10.1186/1471-244X-9-47 (1. 12. 2020).

Hart, Laura M., Jorm, Anthony idr. (2010). Development of Mental Health First Aid Guidelines for Aboriginal and Torres Strait Islander People Experiencing Problems with Substance Use: A Delphi Study. BMC Psychiatry 10, 78, https://doi. org/10.1186/1471-244X-10-78 (5. 10. 2020).

Ingleby, David (2005). Editor's Introduction. Forced Migration and Mental Health Rethinking the Care of Refugees and Displaced Persons. Boston: Springer, 1-27.

Jorm, Anthony F., Korten, Ailsa idr. (1997). "Mental Health Literacy": A Survey of the Public's Ability to Recognize Mental Disorders and their Beliefs about the Effectiveness of Treatment. Medical Journal of Australia 166, 182-186, https://onlinelibrary.wiley.com/doi/abs/10.5694/j.1326-5377.1997.tb140071.x (7. 10. 2020).

Jorm, Anthony F. (2012). Mental Health Literacy: Empowering the Community to Take Action for Better Mental Health. American Psychologist 67/3, 231-243, https://doi. org/10.1037/a0025957 (2. 7. 2019).

Jorm, Anthony F., Kitchener, Betty A., Reavley, Nicola J. (2019). Mental Health First Aid Training: Lessons Learned from the Global Spread of a Community Education Program. World Psyciatry 18/2, 142-143, https://onlinelibrary.wiley.com/doi/ full/10.1002/wps.20621 (2. 6. 2020).

Kanowski, Len G., Jorm, Anthony, Hart, Laura M. (2009). A Mental Health First Aid Training Program for Australian Aboriginal and Torres Strait Islander peoples: Description and Initial Evaluation. International Journal of Mental Health Systems 3, 10, https://doi.org/10.1186/1752-4458-3-10 (5. 1. 2021).

Kirmayer, Lawrence (2012). Editorial: Rethinking Cultural Competence. Transcultural Psychiatry 49/2, 149-164, https://doi.org/10.1177/1363461512444673 (29.11. 2020). Kitchener, Betty A., Jorm, Anthony F. (2002). Mental Health First Aid Training for the Public: Evaluation of Effects on Knowledge, Attitudes and Helping Behavior. BMC Psychiatry 2, 10, https://doi.org/10.1186/1471-244X-2-10 (1. 12. 2018).

Kleinman, Arthur, Benson, Peter (2006). Anthropology in the Clinic: The Problem of Cultural Competency and How to Fix it. PLoS Medicine 3/10, 1673-1676, https:// doi.org/10.1371/journal.pmed.0030294 (12. 3. 2018).

Knežević Hočevar, Duška (2020). Ko je ogroženo najdragocenejše: Stigma nekoliko drugače. Glasnik Slovenskega etnološkega društva 60/2, 5-15.

Lam, Angus Y. K., Jorm, Anthony, F. (2010). Mental Health First Aid Training for the Chinese Community in Melbourne, Australia: Effects on Knowledge about and Attitudes Toward People With Mental Illness. International Journal of Mental Health Systems 4, 18, https://doi.org/10.1186/1752-4458-4-18 (28. 11. 2020).

Lee, Othelia E., Tokmic, Farah (2019). Effectiveness of Mental Health First Aid Training for Underserved Latinx and Asian American Immigrant Communities. Mental Health \& Prevention 13, 68-74, https://doi.org/10.1016/j.mhp.2018.12.003 (4. 1. 2020). 
Lindert, Jutta, Schouler-Ocak, Meryam idr. (2008). Mental Health, Health Care Utilisation of Migrants in Europe. European Psychiatry 23/1, 14-20, http://dx.doi. org/10.1016/S0924-9338(08)70057-9 (10. 8. 2019).

Lipovec Čebron, Uršula (2019). Antropologija in javno zdravje: Izkušnje razhajanja, poskusi približevanja. Etnolog 29/80, 35-55.

Lipovec Čebron, Uršula, Huber, Ivanka (2020). Cultural Competence and Health Care Experiences from Slovenia. Etnološka tribina 43, 68-88, https://doi.org/10.15378/18489540.2020.43.02 (12. 2. 2021).

Liu, Cha-Hsuan, Meeuwesen, Ludwien idr. (2015). Why do Ethnic Chinese in the Netherlands Underutilize Mental Health Care Services? Evidence from a Qualitative study. Transcultural Psychiatry 52/3, 331-352, https://doi.org/10.1177/1363461514557887 (14. 5. 2019).

Mental Health First Aid - International Directory of MHFA Programs, http://www.mhfainternational.org/international-mhfa-programs.html (7. 1. 2021).

Metzl Jonathan M., Hansen, Helena (2014). Structural Competency: Theorizing a new Medical Engagement with Stigma and Inequality. Social Science \& Medicine 103, 126-133, https://doi.org/10.1016/j.socscimed.2013.06.032 (27. 12. 2020).

$\mathrm{Na}$, Sumin, Ryder, Andrew G., Kirmayer, J. Lawrence (2016). Toward a Culturally Responsive Model of Mental Health Literacy: Facilitating Help-Seeking Among East Asian Immigrants to North America. American Journal of Community Psychology 58/1-2, 211-225, https://doi.org/10.1002/ajcp.12085. Epub 2016 Sep 5 (9. 1. 2021).

Nutbeam, Don (2000). Health Literacy as a Public Health Goal: A Challenge for Contemporary Health Education and Communication Strategies into the $21^{\text {st }}$ Century. Health Promotion International 15/3, 259-267, https://doi.org/10.1093/ heapro/15.3.259 (7. 11. 2020).

Ramsden, Irihapet M. (1993). Kawa Whakaruruhau: Cultural Safety in Nursing Education in Aotearoa, New Zealand. Nursing Praxis in New Zealand 8/3, 4-10.

Shaw, Susan J. (2009). The Role of Culture in Health Literacy and Chronic Disease Screening and Management. Journal of Immigrant and Minority Health 11/6, 460467, http://doi.org/10.1007/s10903-008-9135-5 (23. 12. 2020).

WHO (2017). Migrant populations, Including Children, at Higher Risk of Mental Health Disorders, https://www.euro.who.int/en/health-topics/health-determinants/migration-and-health/news/news/2017/04/migrant-populations,-including-children,-at-higher-risk-of-mental-health-disorders (7. 1. 2021).

Wong, Daniel Fu Keung, Li, Jessica C. M. (2012). Cultural Influence on Shanghai Chinese People's Help-seeking for Mental Health Problems: Implications for Social Work Practice. British Journal of Social Work 44/4, 868-885, https://doi. org/10.1093/bjsw/bcs180 (27. 12. 2020). 


\section{SUMMARY}

\section{MENTAL HEALTH AND MIGRATION: THE APPLICABILITY OF THE MENTAL HEALTH FIRST AID PROGRAM Duška KNEŽEVIĆ HOČEVAR, Sanja CUKUT KRILIĆ}

This article discusses the establishment of the mental health literacy program Mental Health First Aid, initially designed in Australia and later transformed for the needs of ethnic minorities and immigrants. In shaping the program, its authors referred to health evidence about the poor mental health of certain social groups on the one hand, and the results of studies that confirmed that not seeking professional help and poor mental health literacy were the main reasons for their poor mental health and well-being. Since the Mental Health First Aid program is grounded in particular Western medical knowledge, the research question reads: What kind of knowledge is preferred to improve the literacy of people with mental health difficulties, including immigrants?

In this line, the article first shortly summarizes the circumstances of the Mental Health First Aid program's establishment in Australia, which was designed to improve participants' knowledge of mental health, certain common disorders (e.g., depression, anxiety, substance abuse, self-harm, suicidal behaviors), and available treatment options. Further, the article focuses on the Mental Health First Aid program's introduction in Aboriginal and immigrant communities. It soon became apparent that the general "one size fits all" approach was not appropriate. Therefore, the program was redesigned in terms of cultural relevancy, competence, and safety. Moreover, evaluation studies of such culturally sensitive programs implied that further adaptations of educational content and approaches were necessary to meet the particular cultural needs of these groups. These endeavors are illustrated by examples of the culturally adapted Mental Health First Aid for Aboriginal people and immigrants in various countries. Besides considering the importance of the cultural dimension of mental health in such programs, the article discusses historical and contemporary vulnerabilities that significantly affect the lived experiences of "culturally different" people with mental health difficulties. In this view, a culture is not only an observable circumstance of the program users but the program providers as well. Finally, such program adaptations question the concept of literacy itself, considering the practice of equal knowledge of the mental health of both the users and providers instead. 